\title{
Patient Preference and Physician Perceptions of Patient Preference for Oral Pharmaceutical Formulations: Results from a Real-Life Survey
}

\author{
Lara MacKenzie-Smith $^{\mathrm{a}}$ Paolo Marchi ${ }^{\mathrm{a}}$ Helen Thorne ${ }^{\mathrm{a}}$ Susan Timeus ${ }^{\mathrm{a}}$ \\ Ryan Young ${ }^{b}$ Perrine Le Calvéb

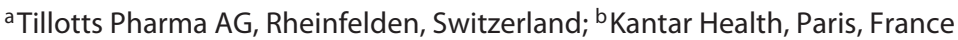

\section{Keywords}

Perceived preference - Adherence · Nonadherence .

Compliance $\cdot$ Ulcerative colitis · Oral therapy

\begin{abstract}
Background: Pharmaceutical treatment prescribed according to patient preference for a formulation may have a positive impact on adherence to treatment and consequently on treatment outcomes. Aim: This study aimed at understanding patient preference for pharmaceutical formulations and attributes that trigger patient preference and physician perception of patient preference. Methods: Between August and September 2017, gastroenterologists and patients with mild to moderate ulcerative colitis from France, Germany, Spain, and the UK participated in an online survey. The investigation was exploratory in nature, and descriptive results are presented. Results: Patient $(n=380)$ preference appears to be driven by the appearance (format, shape, size, and color $-44 \%)$, number of units per administration (39\%), and number of administrations per day (17\%). Gastroenterologist $(n=159)$ preference is instead driven by the number of administrations per day (55\%), number of units per day $(26 \%)$, and tablet size (19\%). Overall, 254 (67\%) patients preferred a tablet formulation, 111 (29\%) preferred granules,
\end{abstract}

and 15 (4\%) other formulations. According to gastroenterologist perception of patient preference, only $49 \%$ of patients prefer tablets, $38 \%$ prefer granules, and $13 \%$ have no preference. After switching from granules to tablets, $25 \%$ patients expressed negative feelings for granules. However, after switching from tablets to granules, $44 \%$ of patients still have positive perceptions of tablets. Among patients receiving tablets ( $n=255), 18$ (7\%) perceived their treatment to be not at all effective versus $16(13 \%)$ patients receiving granules $(n=125)$. A similar proportion of patients in the two groups perceived their treatment as extremely effective (48 vs. $46 \%$, respectively). Conclusions: Patients generally prefer tablets. Patient and gastroenterologist perception of patient preference for different oral drug formulations is triggered by the same attributes but with inverse importance. To improve adherence, patients should be involved in the choice of the treatment formulation. @2018 The Author(s)

Published by S. Karger AG, Basel

\section{Introduction}

Ulcerative colitis (UC) and Crohn's disease (CD) are the two most common forms of inflammatory bowel disease (IBD), a chronic, idiopathic condition affecting more

\begin{tabular}{ll}
\hline KARGER & $\begin{array}{l}\text { @ } 2018 \text { The Author(s) } \\
\text { Published by S. Karger AG, Basel }\end{array}$ \\
E-Mail karger@karger.com & $\begin{array}{l}\text { This article is licensed under the Creative Commons Attribution- } \\
\text { NonCommercial-NoDerivatives 4.0 International License (CC BY- } \\
\text { NC-ND) (http://www.karger.com/Services/OpenAccessLicense). } \\
\text { Www.karger.com/iid }\end{array}$ \\
Usibution of modified material requires written permission. \\
tributis
\end{tabular}


than 1.5 and 2 million individuals in the USA and Europe, respectively. An accelerating incidence in newly industrialized countries is currently being observed [1].

Treatment of the disease is symptomatic, and adherence to treatment has an impact on the course of the disease [2]. Medical treatment is required to induce and maintain remission of IBD, and adherence to treatment has been associated with positive treatment outcomes [35]. On the other hand, nonadherence to treatment has been associated with an increased risk of symptomatic relapse $[6,7]$, decreased quality of life [8], and increased costs of health care due to disease relapse [9]. Poor adherence may be particularly problematic in quiescent disease, since patients lack symptoms that incentivize them to take their medication [10]. In 2010, nonadherence rates ranged between 7 and $72 \%$ in a meta-analysis-based publication including $>4,300$ patients with a diagnosis of IBD, with the majority of the studies included in the analysis reporting an average nonadherence rate of $30-45 \%$ [11].

Several studies have attempted to identify predictors of adherence and future nonadherence. In 2009, Kane et al. [12] demonstrated that positive and negative predictors associated with persistence to treatment change over time. Rectal use of 5-aminosalicylic acid (5-ASA) along with the use of corticosteroids were reported to be positive predictors of persistence to treatment at 3 months, while the use of corticosteroids at 12 months was no longer a positive predictor. In a multicenter, prospective cohort study including 1,558 patients with $\mathrm{CD}$ and 1,054 patients with UC, younger age at diagnosis, flares, feelings of anxiety or depression, and nonadherence were associated with future nonadherence to treatment [13]. A recent study from Bager et al. [2] reported young age and smoking as predictors of nonadherence, while high adherence rates were explained by high patient satisfaction and high degree of shared decision making. A very recent study published by Keil et al. [14] conducted in 198 outpatients with a diagnosis of UC has shown that the patient's education level can significantly influence compliance to treatment. Other variables such as age, gender, marital status, number of doses per day, or the pharmaceutical form of the prescribed treatment had no impact.

Data on patient preference for pharmaceutical formulations and adherence or compliance to treatment are limited, as well as data on physician perception of patient preferences. Depending on the study, the patient population, and the pharmaceutical formulations compared, patient preferences are discordant. However, it appears concordant that prescribing the patient-preferred formulation may lead to a better adherence to treatment [1519].

The present study aims at understanding patient preferences and drivers for patient preference for pharmaceutical formulations, and how physicians perceive patient preferences.

\section{Materials and Methods}

\section{Study Design and Study Population}

This study was conducted between August and September 2017 in 4 European countries (France, Germany, Spain, and the UK). Adult patients newly diagnosed or with a previous diagnosis of mild (defined as "passage of 4 or fewer stools per day [with or without blood]") to moderate (defined as "passage of 4-6 stools per day, little to no fever, or racing heart rate") UC were invited to answer a 30 -min online survey and to complete a conjoint exercise.

Gastroenterologists spending $>50 \%$ of their working time in direct patient care were invited to answer a 20 -min online questionnaire. As no treatment (either active or placebo) was administered to the participants in this study, no ethical committee approval was sought.

\section{Questionnaire for Patients}

Individuals accepting to participate in the online survey were requested to report any past diagnosis of asthma, diabetes, depression, UC, Parkinson disease, high blood pressure, high cholesterol, sleep apnea, anxiety, and acid reflux. The questionnaire was terminated if no diagnosis of UC was reported. A total of 20 questions (see online suppl. File 1; for all online suppl. material, see www. karger.com/doi/10.1159/000493346) to gather information on demographic data, time of diagnosis, dosing schedule, perceived and diagnosed disease severity, pharmaceutical treatment formulation prescribed, treatment history, previously prescribed treatment, and reasons for treatment change were asked either as open, yes/ no, or multiple choice questions. Swallowability of pharmaceutical formulations and perceived efficacy were assessed by means of a nonvalidated visual analogue scale (VAS) from 0 to 10 , where 0 represents the worst outcome ever and 10 the best outcome ever. Reasons to prefer certain pharmaceutical formulations were assessed by rating of complete disagreement (0) or complete agreement (10) for a list of reasons.

\section{Questionnaire for Physicians}

Physicians accepting to participate in the online survey were requested to answer a few screening questions. The questionnaire was terminated when

- they declared not to be a gastroenterologist by training;

- they spent $<80 \%$ of their time in direct patient care as opposed to conducting clinical research and nonclinical activities such as teaching;

- they have been in active clinical practice in gastroenterology for $<3$ years or $>40$ years; or

- they were seeing less than 5 patients with mild or moderate UC during the last month.
MacKenzie-Smith et al. 
For physicians based in the UK only, the questionnaire was also terminated when $<80 \%$ of their professional time was spent in a hospital setting.

The online survey consisted of 19 questions (asked either as open, yes/no, or multiple choice questions) (see online suppl. File 2) to gather information on preferred prescribed pharmaceutical formulations for any disease and for UC, for what type of patient they prefer each type of pharmaceutical formulation, perceived patient preference, and reasons underlying the preference, the proportion of patients adherent/partially adherent/nonadherent to treatment, and underlying reasons. Swallowability of pharmaceutical formulations and attributes triggering patient preferences were assessed by means of a nonvalidated VAS from 0 to 10 , were 0 was the worst outcome ever and 10 the best outcome ever.

\section{Conjoint Exercise}

A conjoint exercise was used to determine the patient and physician preferences. A series of forced-choice questions were asked in a discrete choice experiment, where physicians and patients compare different treatments, 3 at a time. Patients were asked to choose 1 of 3 treatments that they would prefer to take, and the physicians were asked to choose a patient profile that they are most likely to treat with each product type. Each patient/physician was asked 15 different discrete choice tasks. Patients and physicians make a trade-off decision by comparing the attributes of each product (in the case of physicians product vs. patient); based on those choices, one can assess the importance of each attribute in the physician or patient choice for a treatment. The data collected from the conjoint analysis were analyzed using hierarchical multinomial logit Bayesian estimation and provide the percentage of the patient/physician choice that is decided based on each attribute.

Primary and Secondary Objectives

Primary objectives of the study were patient perceptions of swallowability of different drug pharmaceutical formulations, patient preference of tablet versus granule formulations; drivers for patient preferences (e.g., tablet size, dosing schedule, gagging feeling, fear of tablets or granules stuck in the throat/mouth/teeth, amount of water required to take the drug, use in public, packaging, or flavor), and whether these are based on previous experience or feelings.

Secondary objectives of the study were the same as the primary objectives but stratified by participating country, age, gender, health status (induction or maintenance of remission), newly diagnosed medication, and number of concomitant medications; physician perception of patient preferences, both overall and stratified by country, patient age, gender, and health status (induction or maintenance of remission), newly diagnosed medication, and number of concomitant medications, and personal preference of physicians for one or another type of drug forms and drivers for physician preferences (e.g., tablet size, dosing schedule, personal beliefs, or experience reported by patients).

\section{Statistical Analysis}

The presentation of the data is descriptive. Continuous data are presented as mean values \pm standard deviations or median values. Categorical variables are presented as frequency counts with percentages. Hierarchical multinomial logit Bayesian estimation was used to calculate the weight of importance in physician and patient decision making using results from the discrete choice experiment.

\section{Results}

Overall, 539 individuals participated in this study, and 380 of them had a new or previous diagnosis of mild to moderate UC, and 159 were gastroenterologists spending $\geq 50 \%$ of their professional time seeing patients. Demographic characteristics of both subgroups are shown in Table 1.

\section{Medication Intake Behavior and Preferences}

Among the 380 individuals with a diagnosis of UC, 195 patients had mild disease activity. Of these, 73 (37\%), 78 (40\%), and $44(23 \%)$ perceived the severity of their disease as mild, moderate, or severe, respectively. Among the 185 individuals with moderate disease activity, the proportions of patients with perception of the disease severity as mild, moderate, or severe were 8,61 , and $31 \%$, respectively.

Overall, the majority - $255(67 \%)$ - were prescribed tablets to treat any of their medical conditions, while 125 (33\%) were prescribed granules. Medication intake occurs mainly in the morning (82\%) and in the evening (55\%), less in the middle of the day (30\%). Of note, there was no difference in the proportion of individuals taking their medication concomitantly with or independently of meals (53 vs. $47 \%$, respectively). Results on medication intake stratified by pharmaceutical formulations (e.g., tablets vs. granules) are presented in Table 2.

Among the individuals taking 5-ASA tablets, 231 (91\%) reported to swallow the tablet whole; 14 (5\%) declared to mix the tablet with food; 10 (4\%) reported to do something else to swallow the tablet. Individuals taking 5-ASA granules reported to either swallow the granules all at once $(n=88,70 \%)$, chew the granules $(n=16,13 \%)$, mix the granules with food or drinks $(n=13,10 \%)$, or divide the dose into smaller portions to swallow them $(n=8,6 \%)$. Reasons for 5-ASA formulation intake behaviors are reported in Figure 1.

\section{Perceived Effectiveness}

On a VAS scale (0-4 perception of poor effectiveness; 5-7 perception of average effectiveness; $8-10$ perception of high effectiveness), 124 (49\%), 114 (43\%), and 17 (7\%) individuals taking tablets $(n=255)$ perceived the effectiveness of their treatment as high, average, and poor, respectively. In this group, the VAS score for treatment effectiveness was $7.3 \pm 1.92$. Among patients taking granules $(n=125)$, the proportion of patients reporting the same perceived treatment effectiveness were 46,41 , and $13 \%$, with a VAS score for treatment effectiveness of $7.0 \pm 2.19$. 
Table 1. Demographics of patients with ulcerative colitis and gastroenterologists participating in the online survey

\begin{tabular}{|c|c|c|c|c|c|}
\hline \multicolumn{6}{|c|}{ Patients with ulcerative colitis participating in the survey } \\
\hline \multicolumn{6}{|l|}{ Gender, $n(\%)$} \\
\hline Males & $174(46)$ & $30(38)$ & $46(46)$ & $54(54)$ & $44(44)$ \\
\hline Females & $206(54)$ & $50(62)$ & $54(54)$ & $46(46)$ & $56(56)$ \\
\hline Median & 43.0 & 42.5 & 45.5 & 40 & 50.5 \\
\hline Min & 18.0 & 19 & 19 & 18 & 21 \\
\hline $\operatorname{Max}$ & 78.0 & 78 & 69 & 66 & 76 \\
\hline \multicolumn{6}{|l|}{ State of the disease, $n(\%)$} \\
\hline Active ulcerative colitis & $186(49)$ & $55(69)$ & $50(50)$ & $41(41)$ & $40(40)$ \\
\hline In remission & $194(51)$ & $25(31)$ & $50(50)$ & $59(59)$ & $60(60)$ \\
\hline Between 6 and 10 years & $70(18)$ & $12(15)$ & $19(19)$ & $20(20)$ & $19(19)$ \\
\hline Between 11 and 20 years & $63(17)$ & $11(14)$ & $10(10)$ & $18(18)$ & $24(24)$ \\
\hline$>20$ years & $50(13)$ & $7(8)$ & $22(22)$ & $8(8)$ & $13(13)$ \\
\hline \multicolumn{6}{|l|}{ Comorbidities $^{1}, n$} \\
\hline Mean & 2.9 & 2.8 & 3.4 & 3.1 & 2.6 \\
\hline Median & 2.0 & 2.1 & 2.3 & 2.1 & 1.6 \\
\hline \multicolumn{6}{|l|}{ Comorbidities, $n(\%)$} \\
\hline Ulcerative colitis & $380(100)$ & $80(100)$ & $100(100)$ & $100(100)$ & $100(100)$ \\
\hline High blood pressure & $113(30)$ & $21(26)$ & $37(37)$ & $24(24)$ & $31(31)$ \\
\hline Depression & $102(27)$ & $26(33)$ & $37(37)$ & $19(19)$ & $20(20)$ \\
\hline High cholesterol & $99(26)$ & $12(15)$ & $24(24)$ & $39(39)$ & $24(24)$ \\
\hline Granules & $125(33)$ & $26(33)$ & $44(44)$ & $41(41)$ & $14(14)$ \\
\hline \multicolumn{6}{|c|}{ Gastroenterologists participating in the survey } \\
\hline Gastroenterologists, $n(\%)$ & 158 & $38(24)$ & $40(25)$ & $40(25)$ & $40(25)$ \\
\hline \multicolumn{6}{|l|}{ Gender, $n(\%)$} \\
\hline Males & $119(75)$ & $31(80)$ & $31(78)$ & $19(48)$ & $38(95)$ \\
\hline Females & $39(25)$ & $7(20)$ & $9(22)$ & $21(52)$ & $2(5)$ \\
\hline Mean age, years & 47 & 49 & 48 & 44 & 46 \\
\hline Years of clinical experience & 14 & 18 & 15 & 16 & 5 \\
\hline Time spent treating patients, $\%$ & 89 & 89 & 87 & 91 & 86 \\
\hline \multicolumn{6}{|l|}{ Working setting, $n(\%)$} \\
\hline Hospital & $122(77)$ & $30(77)$ & $24(60)$ & $28(70)$ & $40(100)$ \\
\hline Office & $10(6)$ & $1(3)$ & $9(23)$ & $0(0)$ & $0(0)$ \\
\hline Mixed & $27(17)$ & $8(20)$ & $7(17)$ & $12(30)$ & $0(0)$ \\
\hline
\end{tabular}


Table 2. Medication intake stratified by galenic formulation

\begin{tabular}{lcc}
\hline & $\begin{array}{l}\text { Patients taking } \\
\text { tablets }\end{array}$ & $\begin{array}{l}\text { Patients taking } \\
\text { granules }\end{array}$ \\
\hline $\begin{array}{l}\text { Patients, } n \text { (\%) } \\
\text { Administrations per day, } n\end{array}$ & $255(67)$ & $125(33)$ \\
$\quad$ Median & 3 & 2 \\
$\quad$ Min & 1 & 1 \\
$\quad$ Max & 10 & 9 \\
Tablet/sachet per administration, $n$ & \\
$\quad$ Median & 5 & 3 \\
$\quad$ Min & 2 & 1 \\
$\quad$ Max & 20 & 20 \\
Tablet/sachet per day, $n$ & 15 & $63(74)$ \\
$\quad$ Median & & $28(22)$ \\
Time of drug intake, $n$ (\%) & $219(86)$ & $43(34)$ \\
$\quad$ Morning & $86(34)$ & $69(55)$ \\
Middle of the day & $164(64)$ & $56(45)$ \\
$\quad$ Evening & $133(52)$ & \\
Independently of meals & $122(48)$ & \\
$\quad$ With meals & &
\end{tabular}

\section{Preference, Perceived Preference, and Attributes}

Triggering Preference

Among the 380 individuals who responded to the 30-min online questionnaire and conjoint exercise, 254 (67\%) preferred the tablet formulation, 111 (29\%) preferred granules, and 15 (4\%) expressed no preference. Medication switch occurred from granules to tablets $(n=$ $54)$ and vice versa $(n=44)$. In particular, after switching from granules to tablets, most patients have strong negative feelings towards granules. However, after switching from tablets to granules patients still have positive perceptions of tablets (Fig. 2). Around one-third continue to find tablets easy to swallow. Neither age nor gender effects were observed. Treatment change initiative was $81 \%$ by the physician, and reasons for switching formulations included: the physician thought the formulation would be better suited for the patient $(81 \%)$ as well as other reasons (19\%); the initiative was $19 \%$ by the patient, and reasons for switching formulations included: the patient did not like the formulation (64\%), the treatment was no longer effective (19\%), or other (17\%).

Overall, gastroenterologists believe that $49 \%$ of patients prefer tablets, $38 \%$ prefer granules, and $13 \%$ have no preference for either formulation. With regard to personal preference, 90 (57\%) gastroenterologists prefer to prescribe tablets, while 68 (43\%) prefer to prescribe granules. Gastroenterologists reported that patient management is easier when they prescribe their preferred treat- ment formulation. As shown in online supplementary Figure s1, gastroenterologist preference is not driven by the patient profile unless the patient presents with difficulties in swallowing, is nonadherent, and/or has a high pill burden.

The most important attributes triggering individual preference were treatment appearance (44\%), number of units per administration (39\%), and number of administrations per day (16\%). Gastroenterologist preference was triggered by the same treatment attributes but ranked with inverse importance $(19,26$, and $55 \%$, respectively) (Fig. 3). The 5 main reasons to prefer tablets or granules for both individuals and gastroenterologists who participated in the questionnaire are reported in online supplementary Figure s2.

\section{Adherence to Treatment and Perceived Adherence to \\ Treatment}

Out of 380 responding individuals, 149 (47\%) reported to sometimes forget to take their medicine. They reported to have forgotten to take the medication during the last 2 months $1.7 \pm 3.87$ times (mean $\pm \mathrm{SD}$ ). Other nonadherence reported reasons were self-management of the disease (e.g., stopping to take the prescribed treatment when they were feeling better $-21 \%$ ) and forgetfulness in renewing their prescriptions (17\%).

On average, the 159 responding gastroenterologists consider $62 \%$ of their patients to be adherent (adherence was defined as intake of $>80 \%$ of the prescribed treatment), $26 \%$ partially adherent (intake of $>50-79 \%$ of the prescribed treatment), and $13 \%$ nonadherent (intake of $<50 \%$ of the prescribed treatment). Perceived reasons for nonadherence were forgetfulness $(21 \%)$, self-management of the disease (17\%), and missed renewal of the prescription (10\%).

\section{Discussion}

Prescribing pharmaceutical formulations according to patient preferences may lead to better adherence to treatment and as a result a positive impact on treatment of the disease. Our study aimed at understanding patient preferences for pharmaceutical formulations, what triggers their preference, and how their preference is perceived by gastroenterologists.

According to our results, patient and physician preference for one or another pharmaceutical formulation is triggered by the same attributes but with inverse ranking. Particularly, the most selected attributes triggering pref- 

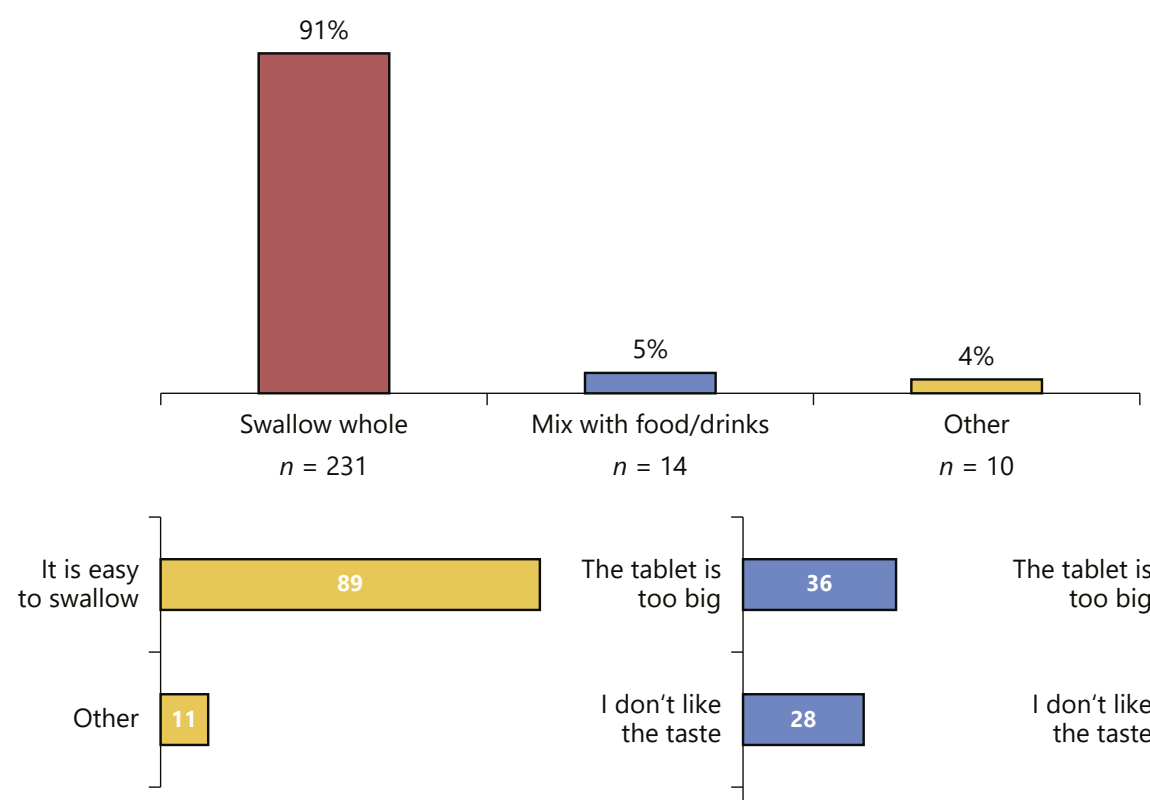

a
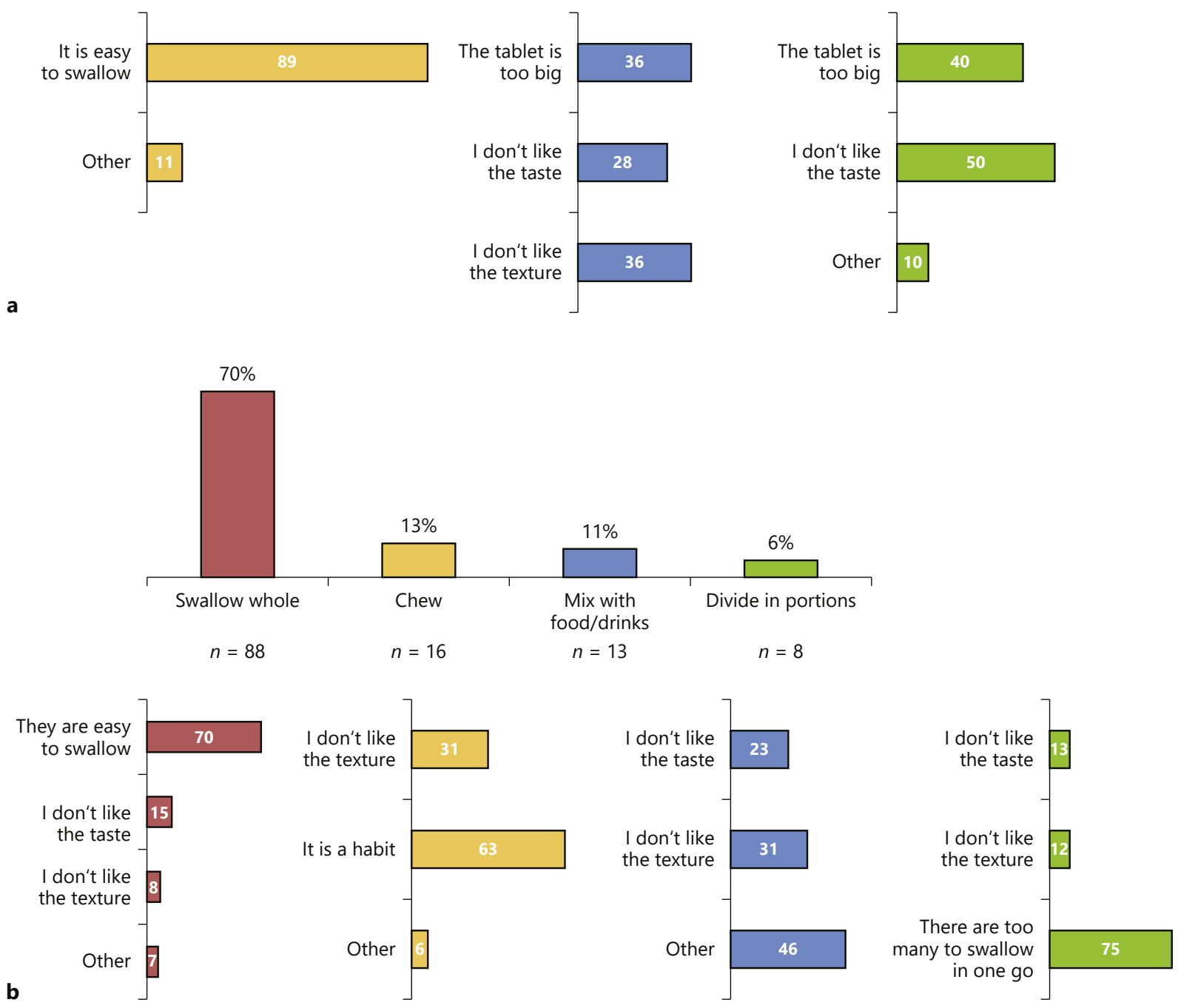

Fig. 1. Formulation intake behaviors. Methods and reasons for taking the prescribed formulation (absolute proportions of individuals) for tablets (a) and granules (b) are presented. 


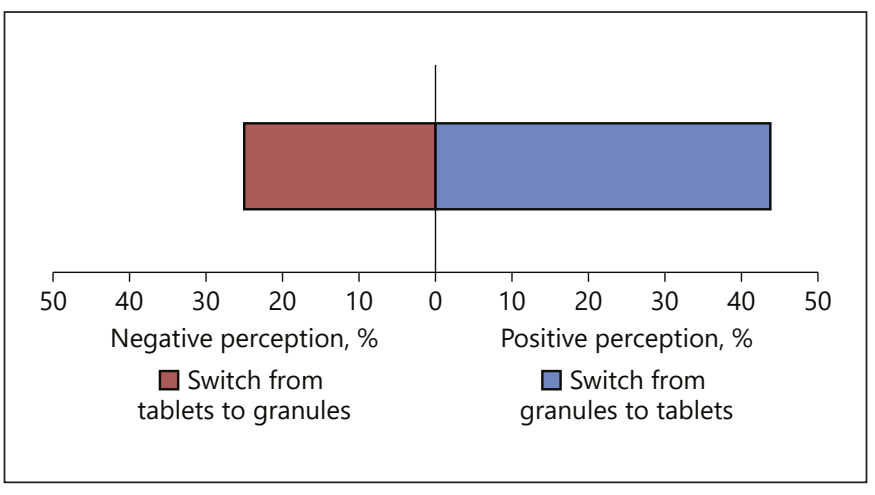

Fig. 2. Patient feelings after a switch from one galenic formulation to another.

erence for a certain treatment were the treatment appearance, the number of administrations per day, and the number of treatments per administration. This result is concordant with the study published by Witticke et al. [19] conducted in 110 primary care patients. This study reported that among all the pharmaceutical formulations considered, tablets with once-daily dosage frequency were the most preferred form, with a high prevalence in the ambulatory setting. The once-daily dosage was also the regimen preferred by patients in the study by Keil et al. [14].

In our study, patients expressed a clear preference for tablets over granules. In particular, patients who switched from granules to tablets expressed negative feelings for the former. Alternatively, those patients who switched from tablets to granules expressed positive feelings for the former. Sixty-four percent of patients reported that the reason for initiating a treatment change was due to not liking the previous formulation. The main reasons for preferring tablets were (i) easy to swallow (49\%), (ii) don't like the texture of granules (32\%), (iii) lots of water needed to swallow granules (29\%), (iv) unpleasant taste of granules (17\%), and (v) tablets taste fine (14\%). On the other hand, the main reasons for preferring granules were (i) easy to swallow (55\%), (ii) tablets are quite large (35\%), (iii) taste fine (20\%), (iv) feeling pressure when swallowing a tablet (18\%), and (v) tablets get stuck in the throat (16\%). From the data above, one can conclude that patient preference for their current formulation is mainly influenced by previous negative feelings for their former formulation. Previous data on patient preference for tablets versus granules are available in the literature. In the German MUKOSA study, patients expressed a marked preference for granules (77\%) over tablets (13\%) [16]. We

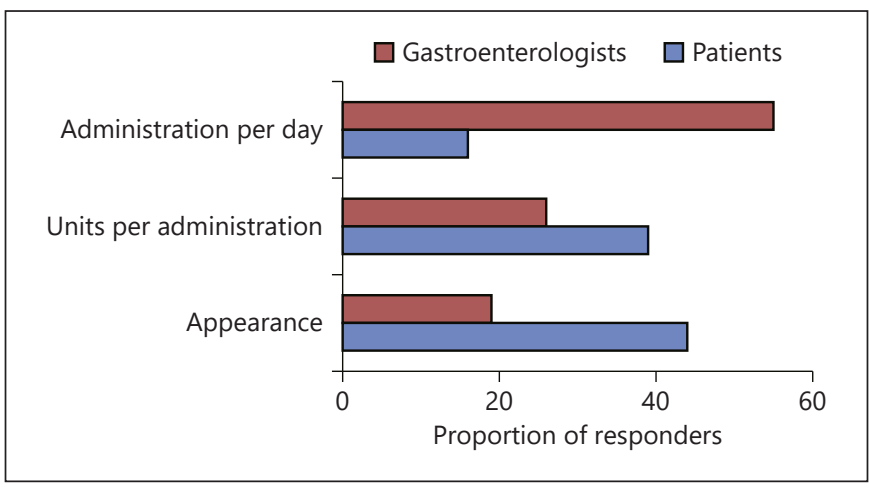

Fig. 3. Attributes triggering preference for a galenic formulation. Patients $(n=380)$ participating in the online survey and gastroenterologists $(n=159)$ were asked to select the 3 most important attributes (where 1 was the most important and 3 the least important) among patient adherence, number of administrations per day, drug appearance, patient lifestyle, patient preference, patient diet, drug brand, and manufacturer.

hypothesize that the reason leading to this discrepancy lies in possible differences between the two study populations. While our study included patients across 4 European countries, the MUKOSA study was conducted only in Germany, and, therefore, one possibility is also that the study results may reflect the preference of the German population, which may not be generalizable to other European populations. According to the study published by Liu et al. [17], granules were the least-preferred formulation along with chewable tablets, while the preferred formulations were dispersible/effervescent tablets and orally disintegrating tablets, but in this case the study population was represented by elderly patients ( $>65$ years of age). In this study, we did not investigate whether tablet size may play a role in adherence. This aspect was investigated by Keil et al. [14] in an observational study; the authors compared the effect of small ( $\leq 17 \mathrm{~mm}$ long) versus big ( $>17 \mathrm{~mm}$ long) tablets and found no significant effect on compliance rates. The compliance rate was $87.3 \%$ with small tablets versus $89.5 \%$ with large tablets $(p=0.695)$.

Adherence rates reported in the literature span from 7 to $72 \%$, with an average of $30-40 \%[1,11,20]$. In our study, the rate of perceived adherence to treatment is concordant with the published literature, as gastroenterologists believe that about $60 \%$ of the patients they treat are adherent to the prescribed therapy. It is noteworthy that both individuals with UC and gastroenterologists believe the main reason driving nonadherence is forgetfulness to take the medications. Forgetfulness seems to affect the 
morning dose significantly less often than the midday and the evening dose [14]. In our study, a relevant proportion of individuals reported treatment intake at midday or in the evening, and, thus, in these subjects forgetfulness is a potential threat for adherence. Considering that the proliferation of mobile phones, and in particular of smartphones, has facilitated the emergence of medical apps, which could help promote treatment compliance. It is indeed encouraging that gastroenterologists are supporting the use of digital tools to promote patient compliance to treatment. However, caution should be used in selecting such apps as a relatively recent systematic review of 238 apps targeting patients with IBD has highlighted noninvolvement of the medical professional in their development, with delivery of incomplete or wrong educational information and absence of a reminder system as a primary functionality [21].

In the MUKOSA study, it was observed that adherence was significantly better when prescriptions were driven by patient preferences [16]. This result correlates with the conclusions of the study from Witticke et al. [19], which state that adaptation of drug regimens to individual preference might be a promising strategy to improve adherence, as well as with those of Keil et al. [14], who concluded that targeted mesalazine therapy based on patient preference can improve adherence to treatment. This concordance seems particularly of interest as the Witticke study did not include granules among the formulations included in the study, in which tablets resulted to be the most preferred pharmaceutical formulation [19]. On the other hand, the MUKOSA study has reported significantly better adherence rates in patients taking granules versus tablets. This result is nonconcordant with that reported in a phase II, double-blind, active-controlled, parallelgroup, multiple-dose, randomized study conducted in 363 adult patients with mild to moderate UC, comparing efficacy and safety of micropellets versus tablet formulations. In this phase II study, compliance to treatment was comparable between treatment arms (98\% in the micropellet group vs. $96 \%$ in the tablet group) [18].

Patient-perceived efficacy for both tablets and granules was high and comparable in our study. Although the proportion of patients who rated tablets and granules as effective or very effective were numerically higher in our study compared to what is reported in the study by Raedler et al. [18] (74.4\% of the patients receiving micropellets rated the therapy as "very good" or "good" vs. $72.9 \%$ of patients receiving tablets), the results of the two studies appear to be concordant.

This study has limitations; therefore, our results need to be interpreted cautiously. This study was explorative in nature and was not powered to detect any statistically significant differences between outcome measures. In addition to this, the absence of bias in the multiple choice questions cannot be guaranteed, despite the effort to provide the responders with the broadest possibilities of realistic choices. Last, our study employed a nonvalidated VAS to assess individual preferences and physician perceptions of individual preferences.

According to our study, patients have a clear preference for tablet pharmaceutical formulations. However, considering the discordant evidence on patient preference available in the literature, further investigations are warranted to firmly state one formulation is preferable to another one. The current available evidence suggests that shared information in the prescription decision making process may lead to better adherence to treatment and, therefore, to better treatment outcomes and reduced costs.

\section{Disclosure Statement}

The study was sponsored by Tillotts Pharma AG. L.M.S., H.T., and S.T. are employees of Tillotts Pharma AG. At the time of submission, P.M. was an employee of Tillotts Pharma AG. R.Y. and P.L.C. are employees of Kantar Health, France.

\section{References}

1 Ng SC, Shi HY, Hamidi N, Underwood FE, Tang W, Benchimol EI, et al. Worldwide incidence and prevalence of inflammatory bowel disease in the 21 st century: a systematic review of population-based studies. Lancet. 2018 Dec;390(10114):2769-78.

2 Bager P, Julsgaard M, Vestergaard T, Christensen LA, Dahlerup JF. Adherence and quality of care in IBD. Scand J Gastroenterol. 2016 Nov;51(11):1326-31.
3 Dignass A, Lindsay JO, Sturm A, Windsor A, Colombel JF, Allez M, et al. Second European evidence-based consensus on the diagnosis and management of ulcerative colitis part 2: current management. J Crohn's Colitis. 2012 Dec;6(10):991-1030.

4 Dignass A, Van Assche G, Lindsay JO, Lémann M, Söderholm J, Colombel JF, et al.; European Crohn's and Colitis Organisation (ECCO). The second European evidence- based Consensus on the diagnosis and management of Crohn's disease: current management. J Crohn's Colitis. 2010 Feb;4(1):28-62. Erratum in: J Crohns Colitis. 2010 Sep;4(3): 353. Dosage error in article text.

5 Simpson SH, Eurich DT, Majumdar SR, Padwal RS, Tsuyuki RT, Varney J, et al. A metaanalysis of the association between adherence to drug therapy and mortality. BMJ. 2006 Jul; 333(7557): 15 . 
6 Khan N, Abbas AM, Bazzano LA, Koleva YN, Krousel-Wood M. Long-term oral mesalazine adherence and the risk of disease flare in ulcerative colitis: nationwide 10 -year retrospective cohort from the veterans affairs healthcare system. Aliment Pharmacol Ther. 2012 Oct;36(8):755-64.

7 Kane S, Huo D, Aikens J, Hanauer S. Medication nonadherence and the outcomes of patients with quiescent ulcerative colitis. Am J Med. 2003 Jan;114(1):39-43.

8 Kane SV. Systematic review: adherence issues in the treatment of ulcerative colitis. Aliment Pharmacol Ther. 2006 Mar;23(5):577-85.

9 Kane S, Joseph R, Shaya F, Winston W. Compliance with 5-ASA products is associated with decreased medical costs. Am J Gastroenterol. 2006;101:436.

10 Wang Y, Parker CE, Feagan BG, MacDonald JK. Oral 5-aminosalicylic acid for maintenance of remission in ulcerative colitis. Cochrane Database Syst Rev. 2016 May; 5(5):CD000544.

11 Jackson CA, Clatworthy J, Robinson A, Horne R. Factors associated with non-adherence to oral medication for inflammatory bowel disease: a systematic review. Am J Gastroenterol. 2010 Mar;105(3):525-39.
12 Kane SV, Accortt NA, Magowan S, Brixner D. Predictors of persistence with 5-aminosalicylic acid therapy for ulcerative colitis. Aliment Pharmacol Ther. 2009 Apr;29(8):855-62.

13 Severs M, Mangen MJ, Fidder HH, van der Valk ME, van der Have $M$, van Bodegraven AA, et al. Clinical Predictors of Future Nonadherence in Inflammatory Bowel Disease. Inflamm Bowel Dis. 2017 Sep;23(9):1568-76.

14 Keil R, Wasserbauer M, Zádorová Z, Kojecký V, Hlava Š, Št'ovíček J, et al. Adherence, risk factors of non-adherence and patient's preferred treatment strategy of mesalazine in ulcerative colitis: multicentric observational study. Scand J Gastroenterol. 2018 Apr;53(4): 459-65.

15 Brunner M, Greinwald R, Kletter K, Kvaternik H, Corrado ME, Eichler HG, et al. Gastrointestinal transit and release of 5-aminosalicylic acid from $153 \mathrm{Sm}$-labelled mesalazine pellets vs. tablets in male healthy volunteers. Aliment Pharmacol Ther. 2003 May; 17(9): 1163-9.

16 Kruis W, Klugmann T, Düffelmeyer M, Ceplis-Kastner S, Reimers B. Detailed Analysis of factors determining patients adherence to therapy in ulcerative colitis (P342). United European Gastroenterol J. 2013;1:A224.
17 Liu F, Ghaffur A, Bains J, Hamdy S. Acceptability of oral solid medicines in older adults with and without dysphagia: A nested pilot validation questionnaire based observational study. Int J Pharm. 2016 Oct;512(2):374-81.

18 Raedler A, Behrens C, Bias P. Mesalazine (5-aminosalicylic acid) micropellets show similar efficacy and tolerability to mesalazine tablets in patients with ulcerative colitis results from a randomized-controlled trial. Aliment Pharmacol Ther. 2004 Dec;20(1112):1353-63.

19 Witticke D, Seidling HM, Klimm HD, Haefeli WE. Do we prescribe what patients prefer? Pilot study to assess patient preferences for medication regimen characteristics. Patient Prefer Adherence. 2012;6:679-84.

20 de Castro ML, Sanromán L, Martín A, Figueira M, Martínez N, Hernández V, et al. Assessing medication adherence in inflammatory bowel diseases. A comparison between a selfadministered scale and a pharmacy refill index. Rev Esp Enferm Dig. 2017 Aug;109(8): 542-51.

21 Con D, De Cruz P. Mobile Phone Apps for Inflammatory Bowel Disease Self-Management: A Systematic Assessment of Content and Tools. JMIR Mhealth Uhealth. 2016 Feb; 4(1):e13. 